\title{
LOGROS ALCANZADOS Y AJUSTES PENDIENTES EN LA CORTE INTERAMERICANA DE DERECHOS HUMANOS
}

\author{
Jean Cadet OdimBA-ON'ETAMBALAKO W.*
}

\begin{abstract}
RESUMEN: A más de un cuarto de siglo de su funcionamiento, la Corte Interamericana ha logrado en diferentes áreas de su funcionamiento una mejora, la legislación que rige su funcionamiento ha mejorado sensiblemente, de manera que ésta se ha colocado entre los órganos más importantes de la OEA, y goza de la confianza de casi todos los países del hemisferio y de sus habitantes; su calidad temporal, la falta de medio para exigir el cumplimiento inmediato de sus sentencias y el reducido número de sus integrantes constituyen algunos puntos a perfeccionar para lograr un eficaz órgano protector de los derechos humanos en la región.
\end{abstract}

ABSTRACT: After almost a quarter of a century in operation, the Interamerican Court of Human rights now functions better in various respects. The legal instruments which govern it have improved perceptibly, to the extent that it has become one of the most important bodies of the OAS and enjoys the confidence of almost all the countries and inhabitants of the Western hemisphere; however, its temporary character, the lack of means for the immediate enforcement of its decisions and the reduced number of its staff are areas for improvement in order for it to become an efficient protector of human rights in the region.

RÉSUMÉ: Après plus d'un quart du siècle de son fonctionnement, la Court Interaméricaine de droit de l'homme a réussi améliorer son fonctionnement dans différentes secteur, la législation qui régis son fonctionnement a sensiblement modifier, de manière a place la Court Interaméricaine de droit de l'homme au Centre des Institutions de l'organisation des Etats américaines bénéficiant de la Confiance des pays de la région et leurs habitants mais pourtant, la no permanence de la Court, la manque des moyens contraignant pour exige l'applications immédiat des ses décision et le numéro réduit des membres de la Court, font partie des déficientes et points a réviser a la hausse pour atteindre une protection optimale des droits de la personne dans la région.

* Doctor en derecho por la UNAM. Investigador honorario del CENADEH, Comisión Nacional de los Derechos Humanos. 


\begin{abstract}
SUMARIO: I. Introducción. II. Funciones y competencia de la corte. III. El proceso contencioso. IV. Supervisión y ejecución de sentencias. V. El procedimiento consultivo. VI. Las medidas provisionales. VII. El futuro del sistema interamericano. VIII. Comentarios personales. IX. Sugerencias. X. Bibliografia.
\end{abstract}

\title{
I. INTRODUCCIÓN
}

Después de observar cuidadosamente los logros alcanzados por la Corte Interamericana de Derechos Humanos y de analizar las problemáticas que ésta necesita superar para la culminación de su desarrollo y cubrir con eficacia las tareas que le han sido atribuidas por la organización de los Estados Americanos (OEA) para los efectos de su importancia en la vida de la sociedad interamericana, la Corte Interamericana de Derechos Humanos ocupa un lugar de privilegio y se encuentra en el nivel más alto en comparación con las instituciones de su rango en el mundo.

El trabajo que viene desarrollando la Corte Interamericana de Derechos Humanos forma la columna vertebral en la protección de los derechos humanos en el continente, también forma parte importante en el desarrollo de las instituciones, sean políticas o jurisdiccionales, involucradas en la defensa y protección de los derechos humanos en el continente americano.

Por estos motivos veremos algunos aspectos de la Corte Interamericana de Derechos Humanos. Sin perder de vista que no se podría agotar un análisis de todos los aspectos de esta institución continental tan importante.

En cuanto a la creación de la Corte Interamericana de Derechos Humanos, la iniciativa de su creación fue presentada por Brasil, lo que permitió que en la Novena Conferencia Internacional Americana ${ }^{1}$ se adoptara la Resolución XXXI denominada Corte Interamericana para Proteger los Derechos del Hombre, en la que se consideró que la protección de esos derechos debe ser garantizada por un órgano jurídico, pues no hay derecho propiamente asegurado sin el amparo de un tribunal competente, ya que tratándose de derechos internacionalmente reconocidos la protección jurídica para ser eficaz debe emanar de un órgano internacional. En 
consecuencia, se encomendó al Comité Jurídico Interamericano la elaboración de un proyecto de estatuto para la creación de una Corte Interamericana destinada a garantizar los derechos del hombre. Sin embargo, el Comité Jurídico Interamericano, en su Informe al Consejo Interamericano de Jurisconsultos del 26 de septiembre de 1949, consideró que la falta de derecho positivo sustantivo sobre la materia constituía un gran obstáculo en la elaboración del Estatuto de la Corte, y que lo aconsejable sería que una convención que contuviera normas de esta naturaleza precediera al estatuto.

Pero fue hasta el 22 de noviembre de 1969 que se adoptó en San José de Costa Rica la Convención Americana sobre Derechos Humanos, por la que se crea (capítulo VIII de la parte II) una Corte Interamericana de Derechos Humanos. ${ }^{2}$

La Asamblea General de la OEA celebrada en La Paz, Bolivia, en 1979, aprobó el Estatuto de la Corte (Resolución 448). El artículo 1o. la define como una institución judicial autónoma que tiene por objeto la aplicación e interpretación de la Convención Americana sobre Derechos Humanos. ${ }^{3}$

Los Estados parte en la convención, en el séptimo período extraordinario de sesiones de la Asamblea General de la OEA (mayo de 1979), eligieron a los primeros siete jueces de la corte y ésta fue instalada oficialmente en San José, Costa Rica, donde tiene su sede el 3 de septiembre de 1979:

La Corte en el curso de su tercer período de sesiones, llevado a cabo del 30 de julio al 9 de agosto de 1980, adoptó su Reglamento y completó los trabajos sobre el Acuerdo Sede Concertado con Costa Rica, en el que se estipulan las inmunidades y los privilegios de la Corte, sus jueces y su personal, así como de las personas que comparecen ante la misma. ${ }^{4}$

La Corte está compuesta por siete jueces de la nacionalidad de los Estados miembros de la OEA, pero elegidos a título personal por mayoría absoluta de votos de los Estados Partes en la Convención Americana, de una lista de candidatos propuestos por esos mismos Estados. Son elegidos

2 Conferencia Especializada Interamericana sobre Derechos Humanos, San José, Costa Rica, 7 a 22 de noviembre de 1969 .

3 Ferrer Mac-Gregor, Eduardo y Carbonell, Miguel, Compendio de derechos humanos, México, Porrúa-Comisión Nacional de los Derechos Humanos, 2004, p. 773.

4 Resolución de la Asamblea General de la OEA, AG/RES.372 (VII-0/78), Resolución aprobada en la séptima sesión plenaria celebrada el 1o. de julio de 1978. 
por seis años y podrán ser reelegidos una vez. ${ }^{5} \mathrm{Al}$ igual que la Comisión, la Corte no es un órgano permanente, por lo que todo el trabajo administrativo y logístico lo asume su Secretaría.

\section{FUNCIONES Y COMPETENCIA DE LA CORTE}

De conformidad con la Convención Americana, la corte ejerce competencia contenciosa (resolución de casos concretos mediante sentencias) y consultiva (emisión de opiniones sobre temas de derechos humanos a interpretar). Estas funciones se distinguen en la materia analizada y las reglas que rigen los respectivos procesos. Al ejercitar su competencia contenciosa, la corte analiza una demanda específica, establece la veracidad de los hechos denunciados y decide si estos constituyen una violación a la Convención Americana. El ejercicio de la competencia consultiva es distinto en su contenido y alcances. Primero, al analizar una petición de opinión consultiva, el tribunal interpreta el derecho internacional, no los hechos específicos. Como consecuencia, no existen hechos por demostrar. 6

Asimismo, mientras que la función contenciosa se resuelve en un proceso judicial en que se ventilan posiciones contradictorias entre las partes procesales (Estado demandado, Comisión Interamericana y la víctima y sus familiares), en la función consultiva tal disputa no existe porque no se refiere a un caso concreto. El ejercicio de la competencia contenciosa de la corte depende necesariamente de la aceptación previa de su competencia por los Estados parte que deberán acatar sus sentencias; en cambio, la competencia consultiva del tribunal no depende del consentimiento de los Estados interesados porque no se ventila caso alguno contra ellos.

Una última diferencia entre ambas competencias se refiere al carácter jurídico de las decisiones emitidas por el tribunal. En el caso del ejercicio de la competencia contenciosa, los tribunales internacionales emiten sentencias y resoluciones en las que determinan la violación al derecho internacional que se denunció y que son vinculantes, tanto para el demandante como para el demandado en el proceso, justamente en virtud de la

5 Véase artículo 4 del Estatuto de la Corte Interamericana de Derechos Humanos.

6 Artículo 2 del Estatuto de la Corte Interamericana de Derechos Humanos en conformidad con los artículos 61, 62 y 63 de la Convención Americana de Derechos Humanos. 
aceptación previa de que el tribunal es competente para solucionar judicialmente el conflicto que ha surgido entre ellos. Contrariamente, en el caso del ejercicio de la competencia consultiva, la corte emite una opinión, la cual no tiene las características de una sentencia ejecutable directamente a nivel interno. No obstante, ello no quiere decir, en modo alguno, que las opiniones consultivas no tengan valor jurídico. Por lo contrario, la competencia consultiva cumple un papel fundamental en el proceso interpretativo de la Convención Americana.

Podría decirse que, mientras el acudir a la competencia contenciosa del tribunal representa un medio para la resolución de conflictos de derechos humanos, el acudir a su competencia consultiva constituye un medio para prevenir conflictos entre los miembros y órganos del sistema interamericano y perfeccionar los instrumentos por medio de los cuales se cumplen sus acuerdos.

\section{EL PROCESO CONTENCIOSO}

A diferencia de la Comisión Interamericana, donde las partes son los peticionarios (personas o grupos de personas sean o no víctimas o familiares de éstas) y el Estado o Estados demandados, en la corte las partes son la misma Comisión Interamericana y los Estados demandados. ${ }^{7} \mathrm{Sin}$ embargo, con la entrada en vigor del nuevo Reglamento de la Corte, actualmente se permite que, una vez admitida la demanda ante la corte, las presuntas víctimas, sus familiares o sus representantes tengan capacidad de actuar ante ese tribunal (locus standi) y, por lo tanto, constituirse como partes. ${ }^{8}$

En su carácter de órgano jurisdiccional del sistema, la corte ha conocido más de treinta casos en ejercicio de su competencia contenciosa, que la faculta para resolver cuestiones relativas a la interpretación y aplicación de la Convención Americana mediante la determinación de la violación o no de los derechos protegidos en ella, y ha determinado las reparaciones respectivas. ${ }^{9}$

7 Véase artículo 28 del Estatuto de la Corte interamericana de Derechos Humanos, aprobado mediante la resolución número 448 adoptada por la Asamblea General de la OEA en su noveno periodo de sesiones celebrado en la Paz, Bolivia, en octubre de 1979.

8 Artículo 23.1 Reglamento de la Corte Interamericana de Derechos Humanos.

9 Artículo 62 y 63 de la Convención Americana. 
La convención, el Estatuto de la Corte y su reglamento prevén la existencia de varias etapas en el procedimiento ante la corte. Es necesario aclarar que estas etapas no siempre se cumplen, ya que la misma convención permite la finalización anticipada del proceso mediante sobreseimiento, solución amistosa, desistimiento o allanamiento. Sin embargo, en términos generales, los casos ante la corte se han desarrollado en las etapas que veremos a continuación.

\section{Fase de excepciones preliminares}

Las excepciones preliminares son defensas procesales que invocan los Estados demandados que, de ser declaradas con lugar, no sería necesario discutir el fondo del asunto, ni demostrar los hechos ni evacuar prueba porque los motivos de forma o de temporalidad objeto de las excepciones darían término al proceso en favor del Estado. El caso más característico resuelto por la corte fue el Caso Cayara contra el Perú, donde el tribunal declaró con lugar la excepción de caducidad de la demanda por haber sido presentada con posterioridad a los tres meses que indica el artículo 51 de la Convención Americana. ${ }^{10}$

No existe una lista taxativa de excepciones preliminares a invocar, sin embargo, a las que más acuden los Estados son las referidas al no agotamiento de los recursos internos (casos contra Honduras) y caducidad de la demanda (Caso Cayara).

Esta es una fase eventual en el proceso contencioso ante la corte, pues la oposición de excepciones preliminares es una defensa que puede no ser utilizada por el Estado demandado por ser renunciable. Sin embargo, en la mayoría de procesos ante la corte los Estados demandados han interpuesto excepciones preliminares.

Es necesario aclarar que la tramitación de las excepciones preliminares no suspende el trámite sobre el fondo del asunto. Sin embargo, en la práctica, la existencia de una fase de excepciones preliminares atrasa la resolución del fondo, pues la corte debe escuchar los alegatos de las partes y deliberar sobre ellas antes de dictar sentencia.

10 Caso Cayara, Excepciones preliminares, Sentencia de 3 de febrero de 1993, Corte IDH (Ser. C) núm. 14 (1994). 


\section{Fase de fondo}

Se divide en una fase escrita y otra oral. La escrita se inicia con la presentación de la demanda ante la corte por parte de la comisión o de un Estado parte, dentro de los tres meses siguientes a la emisión del informe del artículo 50 de la Convención Americana. Junto con la demanda, debe aportarse toda la prueba documental y ofrecerse la testimonial y pericial correspondiente, indicándose en cada caso, el objeto del testimonio o del peritaje. ${ }^{11}$ Por no ser la corte un tribunal penal, los principios que informan la prueba son bastante flexibles, todo con el fin de que sea aceptada la mayor cantidad de prueba posible, pero descartando aquella que sea abundante o innecesaria.

Si la demanda cumple con todos los requisitos señalados por el artículo 33 del Reglamento de la Corte, el presidente autoriza su notificación formal al Estado demandado, al cual se le concede un plazo de dos meses para contestarla. En su respuesta, el Estado debe cumplir con los mismos requisitos exigidos para la comisión en cuanto a la presentación de prueba documental y ofrecimiento de la testimonial y pericial. En caso de que el Estado desee presentar excepciones preliminares, deberá hacerlo en el mismo escrito de contestación.

Una vez que el Estado demandado contesta la demanda, las partes podrían solicitar al presidente la presentación de otros actos del procedimiento escrito, el cual los autorizará. ${ }^{12}$ Con el reglamento anterior, le correspondía al presidente solicitar a las partes si deseaban presentar otros escritos pertinentes, lo que muchas veces era desaprovechado por ellas, ya que los nuevos escritos eran una reiteración de los hechos y argumentos alegados en sus escritos iniciales. Actualmente, en el ejercicio de este derecho (que podríamos llamar réplica y duplica, respectivamente) se solicita a las partes referirse únicamente a hechos y argumentos nuevos.

11 Artículo 50: 1. De no llegarse a una solución, y dentro del plazo que fije el estatuto de la comisión, ésta redactará un informe en el que expondrá los hechos y sus conclusiones. Si el informe no representa, en todo o en parte, la opinión unánime de los miembros de la comisión, cualquiera de ellos podrá agregar a dicho informe su opinión por separado. También se agregarán al informe las exposiciones verbales o escritas que hayan hecho los interesados en virtud del inciso 1.e. del artículo 48. 2. El informe será transmitido a los Estados interesados, quienes no estarán facultados para publicarlo. 3. Al transmitir el informe, la comisión puede formular las proposiciones y recomendaciones que juzgue adecuadas.

12 Artículo 38 del Reglamento de la Corte. 
Durante la fase oral y pública, la corte escucha los testimonios y experticias relevantes en el caso y, en último término, los alegatos finales que las partes en el proceso deseen someter a su consideración.

Asimismo, en varios casos la corte ha fijado audiencias públicas con el propósito de escuchar alegatos respecto de pretensiones específicas, como lo son, por ejemplo, las objeciones o recusaciones a testigos.

Concluido el proceso oral, la corte delibera en privado sobre el fondo del asunto y dicta sentencia, la cual es definitiva e inapelable. Únicamente procede interpretarla a solicitud de alguna de las partes. Por jurisprudencia, la corte ha dejado abierta la posibilidad del recurso de revisión, pero para circunstancias muy especiales, como la aparición de hechos nuevos que podrían modificar el resultado final de la sentencia.

\section{Fase de reparaciones}

El sistema interamericano es un sistema reparador: una vez que la Corte Interamericana determina que ha existido alguna violación a derechos humanos contenidos en la Convención Americana por parte del Estado demandado, se procede a fijar las consecuencias de ese acto como efecto derivado de responsabilidad internacional de ese Estado. Deviene con ello una escala de responsabilidad que principia con la obligación de restituir el derecho violado, y si ello fuera posible la restitución integral del daño. De no ser posible, o en forma colateral, se pueden determinar otras reparaciones como indemnizar por los daños y perjuicios ocasionados, incluyendo otras formas de reparaciones. ${ }^{13}$

La jurisprudencia de la corte ha sido bastante prolija en materia de reparaciones, lo que ha permitido un desarrollo minucioso como se detalla a continuación.

13 Artículo 63: 1. Cuando decida que hubo violación de un derecho o libertad protegidos en esta convención, la Corte dispondrá que se garantice al lesionado en el goce de su derecho o libertad conculcados. Dispondrá asimismo, si ello fuera procedente, que se reparen las consecuencias de la medida o situación que ha configurado la vulneración de esos derechos y el pago de una justa indemnización a la parte lesionada. 2. En casos de extrema gravedad y urgencia, y cuando se haga necesario evitar daños irreparables a las personas, la Corte, en los asuntos que esté conociendo, podrá tomar las medidas provisionales que considere pertinentes. Si se tratare de asuntos que aún no estén sometidos a su conocimiento, podrá actuar a solicitud de la comisión. 


\section{A. Daños materiales}

\section{a. Lucro cesante}

En cuanto a la indemnización por lucro cesante, se ha entendido que equivale al monto de los ingresos que las víctimas o sus sucesores recibirían a lo largo de su vida laboral si no hubiese ocurrido la violación a sus derechos.

La base para calcular el lucro cesante es variable y depende de las circunstancias de cada caso. Mientras que en los casos Velásquez Rodríguez y Godínez Cruz se tomó como base para su liquidación el ingreso devengado por las víctimas en el momento de su desaparición proyectado hasta el momento de su jubilación obligatoria según lo dispuesto por la ley interna, partiendo del sueldo que percibían, en los casos Aloeboetoe y otros, Neira Alegría y otros, y el amparo, al no depender las víctimas de un salario fijo, se tuvo que tomar como base para la liquidación, el salario mínimo vital o el valor de la canasta básica alimentaria. A ese monto proyectado a futuro, se le suman los intereses corrientes desde la fecha de los hechos hasta la de la sentencia.

En todos los casos, para efectos de proyectar a futuro los ingresos que percibiría la víctima, se toma en cuenta la expectativa de vida en el país correspondiente.

\section{b. Daño emergente}

Normalmente se entienden como los gastos efectuados por las víctimas o sus familiares con motivo de sus gestiones para investigar y sancionar los hechos que vulneraron los derechos de las víctimas. En tal sentido, todos los gastos deben ser demostrados con prueba idónea y se le reintegran a la persona que incurrió en los mismos. Pero aún cuando no se haya presentado prueba suficiente, la corte ha hecho estimaciones compensatorias por gastos incurridos en sus distintas gestiones en el país utilizando el principio de equidad.

Referente a las costas ante la corte, el hecho de que el individuo tenga capacidad de actuar (locus standi) a partir de la reforma al reglamento de 2000, se cambió el panorama con respecto al reconocimiento de las costas en que incurra el individuo en la protección de sus derechos ya 
que no está obligado a litigar bajo la égida de la comisión y puede optar, a su criterio, por la contratación de servicios profesionales privados.

A partir del Caso Garrido y Baigorria, la jurisprudencia de la corte dio un giro fundamental al reconocer el pago de gastos y costas en todas las etapas del proceso internacional, así como en el proceso interno, ya que reconoció que para que un caso llegue hasta la Corte Interamericana, es indispensable ver como un todo los distintos procesos que se deben establecer hasta llegar a la etapa final ante la corte.

\section{B. Daños no patrimoniales}

Dentro de esta categoría, se incluye en particular, la indemnización por daños morales por medio de distintas formas de satisfacción:

\section{a. Daño moral}

En materia de derechos humanos, es quizás el daño que más se justifica resarcir, ya que resulta evidente y propio de la naturaleza humana que toda persona sometida a las agresiones y vejámenes que representan la violación de los derechos humanos, experimente un daño moral. Los criterios para su estimación siempre los ha basado la corte con base en el principio de equidad.

\section{b. Satisfacción no patrimonial}

Son medidas a cargo del Estado tales como la investigación de los hechos relativos a la demanda, el castigo de los responsables de esos hechos o la reivindicación de la memoria de las víctimas, como se reconoció por primera vez en el Caso Villagrán Morales y otros contra Guatemala respecto a los "niños de la calle" que fueron víctimas del Estado. ${ }^{14}$

La Corte Interamericana tiene la facultad de ordenar reparaciones junto con la decisión de fondo, o bien, puede condenar en abstracto y reservar su determinación para una etapa procesal posterior. No existe un procedimiento específico en el Reglamento de la Corte para determinar las reparaciones. El nuevo reglamento únicamente contiene un artículo

14 Caso Villagrán Morales y otros, Resolución de la Corte de 16 de abril de 1997, reimprimido en 1997, Informe Anual de la Corte Interamericana de Derechos Humanos [137], OEA/Ser.L/ V/III.39, Doc. 5 (1998). 
que dispone que "cuando en la sentencia de fondo no se hubiere decidido específicamente sobre reparaciones, la corte fijará la oportunidad para su posterior decisión y determinará el procedimiento".

Como el reglamento no establece un procedimiento específico para las reparaciones, se aplica en forma supletoria y por analogía, las normas procesales referentes al proceso contencioso.

La justificación de esta etapa de reparaciones se fundamenta en la obtención de elementos de prueba suficientes, incluyendo experticias, según el grado de dificultad de cada caso, al número de beneficiarios y a la naturaleza misma de las violaciones. La práctica procesal inicial de la corte había sido otorgar a las partes un plazo prudencial para que llegasen a un acuerdo o solución amistosa, el cual era estudiado, y en su caso, homologado por el tribunal. Esa práctica no ha vuelto a ser utilizada por la corte debido a que prácticamente las partes no han llegado a acuerdos de reparaciones, por lo que se prescinde de esa oportunidad para iniciar la etapa procesal de reparaciones, para lo cual se les brinda a las partes un plazo para que presenten los escritos sobre el alcance, contenido, montos y prueba de las reparaciones.

No obstante, nada impide que aún cuando se inicie esta etapa de reparaciones, las partes pueden llegar a una solución amistosa por su cuenta (artículo 56.2 del reglamento), para lo cual la corte deberá verificar que el acuerdo sea justo. Ejemplo de ello es el Caso Benavides Cevallos contra Ecuador. ${ }^{15}$

Con la aplicación del artículo 23 del Reglamento de la Corte que permitió participación (locus standi) a las víctimas, sus representantes o sus familiares en todas las etapas ante la corte, se plantea la discusión del papel que deben realizar la corte y la comisión interamericanas en esta fase procesal.

Ello ha permitido ver con claridad que, ahora más que nunca, la comisión puede realizar con mejor desempeño su función de promoción y protección de los derechos humanos, donde sus alegatos no se circunscriban a cuestiones meramente indemnizatorias para las víctimas, sino centrarse en aspectos más generales que sí son parte de su naturaleza institu-

15 Artículo 56. Sentencia de reparaciones. 1. Cuando en la sentencia de fondo no se hubiere decidido específicamente sobre reparaciones, la Corte fijará la oportunidad para su posterior decisión y determinará el procedimiento. 2. Si la Corte fuere informada de que el lesionado y la parte responsable han llegado a un acuerdo respecto al cumplimiento de la sentencia sobre el fondo, verificará que el acuerdo sea justo y dispondrá lo conducente. 
cional, como por ejemplo, tratar cuestiones relacionadas con otras formas de reparación, verbigracia, investigación de los hechos y castigo a los responsables, falta de adecuación de leyes o actos que constituyeron la violación de los derechos establecidos en relación con la Convención Americana, la no repetición de los hechos y, en general, todo aquello que guarde relación con una reparación justa y acorde con el objeto y fin de la convención.

En cambio, la víctima o sus familiares son la parte llamada a demostrar las cuestiones indemnizatorias por tener a su alcance los datos y pruebas que se requieran para ello. La anterior división de funciones se aplicó en forma muy clara en las reparaciones en el Caso Castillo Páez contra Perú.

Una vez que ha finalizado la etapa de presentación de escritos sobre reparaciones - lo que podríamos denominar fase escrita - la Corte Interamericana, como práctica procesal, convoca a una audiencia pública para que las partes evacuen sus pruebas testimoniales o periciales y presenten verbalmente sus alegatos sobre las reparaciones.

Posteriormente, se inicia la fase deliberativa de las reparaciones donde se emite una sentencia, de conformidad con el artículo 63.1 de la Convención Americana. Un componente importante de esa sentencia es que, aparte de la determinación de las reparaciones, establece un plazo para que el Estado cumpla con las mismas, que por lo general, es de seis meses.

\section{SUPERVISIÓN Y EJECUCIÓN DE SENTENCIAS}

La corte generalmente se reserva, en su sentencia de reparaciones, la facultad de supervisar el cumplimiento de su fallo. La supervisión de sentencias es una labor que requiere cuidadoso estudio y detenida consideración. Sin embargo, constituye también la etapa en la que la labor de la corte alcanza materialmente a aquellas personas para las cuales se ha concebido el sistema de protección a los derechos humanos y en la cual se concretan, de manera más evidente, los beneficios de sus actividades.

Esta etapa consiste en determinar si el Estado encontrado responsable ha cumplido con sus obligaciones en la forma y tiempo previstos. El fundamento de esta etapa de supervisión es consustancial con la naturaleza misma de todo tribunal. 
Los actos que realiza la corte dentro de su obligación de supervisión, van a depender de la naturaleza de lo resuelto en las sentencias de reparaciones. En unos casos, como los de Honduras, debía determinar el pago del monto de dinero fijado como indemnización a los familiares de las víctimas y que se establecieran los fideicomisos en favor de los beneficiarios menores; en otros casos más complejos, la labor es un poco más detallada, ya que además de supervisar esas mismas obligaciones, debe analizar el informes, reaperturas de escuelas, dispensarios médicos, etcétera ( $c f r$. Caso Aloeboetoe y otros). ${ }^{16}$ Pero quizás sean las otras formas de reparación que ordene la corte, las que presenten mayor dificultad en su supervisión, por ejemplo, a la obligación de investigar los hechos y procesar o condenar a los responsables, obligación que ha sido establecida desde los primeros casos resueltos por la corte y que se ha repetido en todas las sentencias posteriores. A la fecha, en ningún caso se ha dado cumplimiento cabal a esta importante obligación.

Quizás la parte más delicada del sistema de protección de derechos humanos sea la referida a las reparaciones y su cumplimiento por tener relación intrínseca con la eficacia jurídica de las sentencias de un tribunal.

Consiente de ello, y para evitar que los fallos de la corte se quedaran en una sanción de tipo moral, la Convención Americana, en forma atinada, dispuso en su artículo 68.2. ${ }^{17}$

No obstante, la verdadera fuerza conminatoria de los fallos de la corte debe radicar en el mismo compromiso de los Estados parte en la de cumplir con la decisión de la corte, tal y como lo dispone el artículo 68.1 de la convención, que refiere al compromiso de los Estados de cumplir las decisiones de la corte. Ese compromiso no puede utilizarse para disminuirle fuerza coercitiva a los fallos, ya que, por el contrario, es una obligación que tienen los Estados parte de respetar los derechos y libertades contemplados en la convención de conformidad con el artículo 1.1 de la misma. Precisamente, la Convención Americana adquiere una eficacia de la más alta importancia práctica por operar como derecho interno de aplicación inmediata por los órganos de los Estados parte y por aplicarse en el marco del derecho internacional.

16 Caso aloeboetoe y otros. Reparaciones (artículo 63.1 Convención Americana sobre Derechos Humanos), sentencia de 10 de septiembre de 1993 en el Caso aloeboetoe y otros.

17 La parte del fallo que disponga indemnización compensatoria se podrá ejecutar en el respectivo país por el procedimiento interno vigente para la ejecución de sentencias contra el Estado. 
Ello no impide que el artículo 68.1 podría verse reforzado por las legislaciones internas por la obligación que tienen, de conformidad con el artículo 2 de la Convención Americana, de adoptar disposiciones de derecho interno para garantizar el ejercicio de los derechos y libertades que no estuvieran garantizados por esas legislaciones. En otras palabras, hacer que los fallos de la Corte Interamericana, además de obligatorios, sean ejecutorios.

\section{EL PROCEDIMIENTO CONSULTIVO}

La Corte Interamericana está facultada por el artículo 64 de la convención para emitir consultas con referencia a la interpretación de la convención o de otros tratados concernientes a la protección de los derechos humanos en los Estados americanos. ${ }^{18}$ Según pronunciamientos de la corte en diversas opiniones, su competencia consultiva se extiende a la interpretación de un tratado siempre que esté directamente implicada la protección de los derechos humanos en un Estado miembro del sistema interamericano. Esta amplia interpretación puede llegar a cubrir tratados que han sido suscritos dentro de sistemas regionales distintos al interamericano, incluyendo el sistema universal de protección a los derechos humanos. Asimismo, también autoriza a la corte a interpretar la Declaración Americana de los Derechos y Deberes del Hombre que, a pesar de no ser un tratado en los términos de la Convención de Viena sobre el Derecho de los Tratados, da contenido a varias de las disposiciones incluidas en la Convención Americana y a la Carta de la OEA.

Asimismo, la corte, a solicitud de un Estado miembro de la organización, podrá darle opiniones acerca de la compatibilidad entre cualquiera de sus leyes internas y los mencionados instrumentos internacionales. Esta posibilidad es particularmente interesante cuando el Estado solicita la opinión consultiva con respecto a proyectos de ley no implementados aún, con lo cual la corte asume una especie de consulta de convencionalidad. ${ }^{19}$

18 Artículo 64. 2. La Corte, a solicitud de un Estado miembro de la Organización, podrá darle opiniones acerca de la compatibilidad entre cualquiera de sus leyes internas y los mencionados instrumentos internacionales.

19 Artículo 64.1. Los Estados miembros de la Organización podrán consultar a la Corte acerca de la interpretación de esta convención o de otros tratados concernientes a la protección de los derechos humanos en los Estados americanos. Asimismo, podrán consultarla, en lo que les compete, 
Esta situación se presentó en la Opinión consultiva OC-4/84, cuando el gobierno de Costa Rica solicitó a la corte una opinión sobre la compatibilidad de algunas eventuales modificaciones a su Constitución Política, así como en la Opinión consultiva OC-12, respecto a un proyecto de ley sobre doble instancia en materia penal.

En un proceso consultivo, además, la corte generalmente invita a todos los Estados y órganos legitimados para que presenten sus observaciones escritas sobre el asunto que ha de resolver.

En su opinión consultiva OC-1/82, la Corte Interamericana estableció que la amplitud de términos en que está formulada su competencia en materia consultiva no implica una ausencia de límites en el ejercicio de esta función y ha sido especialmente cuidadosa al analizar si debe o no absolver una consulta específica y el impacto que su actuación tendrá en el marco general del sistema interamericano y particularmente sobre individuos.

De esta manera, la corte ha establecido que no absolverá consultas que tengan como efecto debilitar o duplicar su función contenciosa o "alterar, en perjuicio de la víctima, el funcionamiento del sistema de protección previsto por la Convención".

\section{LAS MEDIDAS PROVISIONALES}

Un campo que requiere particular estudio es el referido a la potestad del tribunal de requerir, a solicitud de la comisión o motu propio, la adopción de medidas urgentes o provisionales, potestad que le es otorgada por el artículo 63.2 de la convención, que establece: en casos de extrema gravedad y urgencia, y cuando se haga necesario evitar daños irreparables a las personas, la corte, en los asuntos que esté conociendo, podrá tomar las medidas provisionales que considere pertinentes. Si se tratare de asuntos que aún no estén sometidos a su conocimiento, podrá actuar a solicitud de la comisión. ${ }^{20}$

los órganos enumerados en el capítulo X de la Carta de la Organización de los Estados Americanos, reformada por el Protocolo de Buenos Aires.

20 Artículo 63.2. En casos de extrema gravedad y urgencia, y cuando se haga necesario evitar daños irreparables a las personas, la Corte, en los asuntos que esté conociendo, podrá tomar las medidas provisionales que considere pertinentes. Si se tratare de asuntos que aún no estén sometidos a su conocimiento, podrá actuar a solicitud de la comisión. 
Las medidas adoptadas por la corte han revelado ser un instrumento de excepcional importancia en la protección de eventual material probatorio ante la corte y de la vida e integridad personal de testigos en los procesos que ante ésta se desarrollan.

La extensa práctica de la corte en materia de medidas provisionales ha permitido también determinar ciertos problemas en relación con la aplicación de estos mecanismos. Uno de ellos es el referido a la situación que se presenta cuando las medidas se solicitan con respecto a un asunto que no se encuentra en trámite ante la corte. Esta potestad ha sido vista como un gran avance en el derecho procesal de los derechos humanos. $\mathrm{Su}$ valor radica en que los derechos que puedan ser violados están protegidos en una etapa anterior a la conclusión del procedimiento ante la Comisión Interamericana.

Sin embargo, en este supuesto, la corte no cuenta con amplio material probatorio respecto de la existencia de la situación de extrema gravedad y urgencia, y actúa otorgando a la solicitud de la comisión un alto valor presuntivo.

La preocupación básica con respecto a las medidas provisionales es la prolongación excesiva de las mismas, lo que desvirtúa su naturaleza y, a la postre, resta efectividad a un mecanismo concebido como una herramienta de excepción. En efecto, las medidas provisionales, como su nombre lo indica, deben tener un carácter temporal.

La Comisión Interamericana también puede adoptar medidas de carácter preventivo cuando el caso está en su conocimiento y responden a los mismos presupuestos de las medidas provisionales de la corte, sólo que se le conocen con el nombre de medidas cautelares (artículo 25, Reglamento de la Comisión).

\section{EL FUTURO DEL SISTEMA INTERAMERICANO}

El futuro del sistema interamericano está íntimamente ligado con el de la comisión y la corte, todo lo cual ha desembocado en una iniciativa de "fortalecimiento" que inició como proceso de "reforma" a instancias del secretario general de la OEA, señor César Gaviria Trujillo en 1996 pero que, luego de la inactividad en que quedó sumido, fue retomado por la corte y el gobierno de Costa Rica a partir de 1998. Dentro de ese marco, Costa Rica promovió un debate más amplio, menos defensivo y más constructivo que el de 1996, lo que incidió en un proceso de forta- 
lecimiento, más que de reforma, con la inclusión de todos los órganos del sistema y la convocatoria a organizaciones de la sociedad civil, legisladores, universidades y demás consorcios de entidades involucradas con el quehacer de la promoción y protección de los derechos humanos en la región.

Ello permitió poner a prueba el estatus consultivo de las organizaciones no gubernamentales ante la OEA a lo largo de un ciclo de consultas mediante consorcios de agrupaciones nacionales y regionales que han tenido un papel fundamental en todo el proceso, el cual se caracterizó por las siguientes etapas impulsadas a partir de finales de 1998: la celebración de la semana de derechos humanos en Costa Rica; la convocatoria y celebración del Trigésimo Aniversario de la Convención Americana sobre Derechos Humanos, Cuadragésimo de la Comisión Interamericana y Vigésimo Aniversario de la Corte Interamericana de Derechos Humanos, actividad que fue considerada acto oficial del Sistema Interamericano de Derechos Humanos en noviembre de 1999; realización de un diálogo informal de cancilleres sobre el tema del fortalecimiento del sistema en que participaron las delegaciones de los veintiséis países americanos y el secretario general de la OEA, en la que se conformó un Grupo de Trabajo ad-hoc que presentó luego, en febrero de 2000, un plan de acción para el fortalecimiento y desarrollo del Sistema Interamericano de Derechos $\mathrm{Hu}-$ manos que incluía, entre otros, dotación de presupuesto adecuado para los órganos del sistema y un proyecto de Protocolo a la Convención Americana para otorgarle a las víctimas de violaciones de derechos humanos, jus standi ante la Corte Interamericana. Como se sabe, este último paso todavía no ha sido dado por la Asamblea General de la OEA.

Esa apretada síntesis de iniciativas, desembocó con la organización y realización de la XXXI Asamblea General de la Organización de los Estados Americanos, en San José, Costa Rica, en junio de 2001, cuyo tema central estuvo dedicado al fortalecimiento del Sistema Interamericano de Derechos Humanos. En esa oportunidad, se abrieron más espacios para que las organizaciones de la sociedad civil pudieran manifestarse más ampliamente con sus pliegos de propuestas que habían sido elaboradas mediante un trabajo de reuniones nacionales y regionales en 
forma paralela a todo el proceso de fortalecimiento del sistema interamericano. ${ }^{21}$

Hoy, la responsabilidad final de asumir los retos de un fortalecimiento real del sistema interamericano descansa en los órganos políticos de la OEA y, especialmente, en la Asamblea General. La comisión y la corte ya hicieron lo propio modificando y armonizando sus reglamentos permitiéndole capacidad de actuar a las víctimas ante la corte, flexibilizando criterios de envío de casos al tribunal y reduciendo ostensiblemente los plazos durante las distintas fases procesales ante la comisión y la corte.

A título de conclusión me gustaría emitir unas opiniones personales las cuales considero de suma importancia para la mejora de la Corte Interamericana de Derechos Humanos. Quiero también recordar en forma de resumen que los jueces de esta corte son elegidos por los Estados parte de la OEA. Una vez nombrados, éstos se convierten en funcionarios internacionales, razón por la cual no actúan en la defensa de sus países de origen.

Las funciones de la Corte Interamericana de Derechos Humanos son:

1. La función consultiva, en virtud de la cual interpreta las disposiciones de la Convención Americana sobre Derechos Humanos. Pero, ¿qué quiere decir interpretar? Se refiere a la capacidad que la corte tiene para dar a conocer, tanto a los Estados miembros como a los organismos

21 Véase los seis puntos de la resolución de la Asamblea General Ordinaria de la OEA de junio 2001, que señalamos a continuación: "Visto el informe de la Secretaría General sobre cumplimiento de la resolución AG/RES. 1761 (XXX-O/00), Programa Asamblea General Modelo de la OEA. Resuelve: 1. Alentar una vez más a los Estados Miembros a que continúen apoyando el Programa Asamblea General Modelo de la OEA y a que efectúen contribuciones voluntarias a la Secretaría General con el fin de ayudar a financiar la infraestructura y el apoyo logístico necesarios para celebrar los períodos ordinarios de sesiones de la Asamblea General Modelo para Universidades fuera de la sede y en los idiomas oficiales de la OEA. 2. Reconocer la labor extraordinaria, la dedicación infatigable y el entusiasmo del Consejo Docente que creó el Programa Edgar Maya de la Asamblea General Modelo de la OEA como programa autofinanciado y realizado en Washington, D. C., que ha aumentado continuamente la participación de universidades de los Estados Miembros. 3. Instar a los Estados Miembros a hacer extensivo ese apoyo a la realización de los períodos ordinarios de sesiones de la Asamblea General Modelo para estudiantes de secundaria. 4. Alentar a los Estados Miembros a ofrecer sus países como sede de períodos de sesiones de la Asamblea General Modelo para universitarios y estudiantes de secundaria. 5. Solicitar al Secretario General que reitere la invitación a los Observadores Permanentes y a las organizaciones e instituciones interesadas a hacer aportes para facilitar la realización de los períodos ordinarios de sesiones de la Asamblea General Modelo, tanto para universidades como para colegios secundarios. 6. Solicitar a la Secretaría General que presente al Consejo Permanente un plan anual de actividades del Programa Asamblea General Modelo de la OEA, junto con un plan financiero para su ejecución, e informes semestrales sobre las actividades que contengan información concisa sobre la consecución de las metas". 
de la OEA, el espíritu de cada uno de los artículos contenidos en dicha convención a fin de ayudar a los jueces nacionales en su trabajo sobre la protección de los derechos humanos. Pues, si alguno de ellos actuara en contra de esa convención o sin entender bien lo que esta quiere decir, estaría violándola y eso podría llevar al Estado correspondiente ante la Corte Interamericana.

Cabe decir que la función consultiva de la corte no se reduce sólo a interpretar el contenido de la Convención Americana, también puede hacerlo respecto a otros instrumentos relacionados con la protección y promoción de los derechos humanos de los que los Estados americanos se han hecho parte.

2. La función contenciosa, porque juzga y emite sentencia como un tribunal para resolver las controversias que se sometan a ella respecto a la aplicación de la propia Convención Americana y de otros instrumentos que hayan firmado los Estados miembros de la organización. Por ello, al recibir cada caso la corte debe evaluar si el derecho presuntamente violado está protegido por la convención o por alguno de los otros instrumentos referidos.

Resulta pertinente señalar que la Corte Interamericana no es un tribunal penal. Esto significa que la creación de la Corte Penal Internacional es una ampliación en la protección de los derechos humanos especiales, pues se encarga de juzgar solamente las multiformes violaciones de derechos humanos en el marco penal. Por ello, la Corte Penal Internacional no puede juzgar violaciones a derechos humanos que no sean genocidio o crímenes contra la humanidad. Además, en esta corte penal es posible juzgar a los individuos que actúan en contra de la humanidad o que participan en los genocidios; en cambio, en el ámbito de la Corte Interamericana de Derechos Humanos no se prevé esta posibilidad porque se supone que los derechos humanos son violados solamente por los funcionarios del Estado, bajo la cobertura de este.

\section{COMENTARIOS PERSONALES}

En cuanto al procedimiento ante la Corte Interamericana, es necesario decir que hay tres etapas: la del escrito, el cual debe llegar ante la corte por la vía de la Comisión Interamericana de Derechos Humanos, porque aún no se abre la posibilidad de que el individuo cuyos derechos humanos ha violado el Estado acuda directamente ante aquélla; la de la 
entrega del expediente escrito del caso por parte de la comisión, y la de la parte testimonial de los testigos, junto con la presentación de las pruebas.

Cabe subrayar que el sistema interamericano juzga solamente los derechos violados de particulares; por ello, en él no hay posibilidad de enjuiciar los derechos comunitarios o sociales quebrantados si no se ha infringido directamente algún derecho específico de los individuos, pues para que la corte proceda debe haber una víctima concreta del derecho violado.

Condiciones de admisibilidad; estas son importantísimas porque si no se cumplen el caso no es admitido en la corte. Lejos de entrar a citar cada una de esas condiciones, lo que me interesa aquí es aclarar que el hecho de que un caso esté ante la Comisión Nacional de los Derechos Humanos no impide que éste pueda llegar a la corte. ¿Por qué? Porque esta institución no es un organismo jurisdiccional. La creación de la Corte Interamericana fue para dar seguridad jurídica a los habitantes de los países miembros de la organización que han aceptado su competencia jurisdiccional. En cambio, se impide el procedimiento ante la corte si el caso se encuentra en algún otro tribunal.

Excepciones preliminares; es necesario observar desde el principio si no hay elementos que impidan el procedimiento ante la corte.

Las declaraciones de los testigos, los dictámenes periciales y los documentos son algunos tipos de pruebas que se presentan ante la Corte Interamericana.

La sentencia; la mayoría de la gente, cuyos derechos han sido violados, olvida que con una sentencia se puede: ganar y permanecer en la cárcel; ganar y no estar establecida la reparación del derecho violado; ganar y perder. Por eso, el cuerpo de la sentencia es un elemento tan importante para quien tiene la oportunidad de hablar sobre el procedimiento jurisdiccional. De hecho, los abogados debemos explicar a la gente que la sentencia no se trata sólo de ganar o perder. Porque puede parecer que se perdió, por ejemplo, al recibir una sentencia que nos obliga a pagar 5,000 pesos en lugar de 20,000, que es otra forma de ganar.

La ejecución de la sentencia; cuando ésta establezca la reparación del daño, propongo que la Corte Interamericana busque los mecanismos necesarios para pagar directamente a la persona cuyo derecho ha sido violado. Pues, en la mayoría de los casos hay que esperar el cambio de la Pre- 
sidencia de la República para que el Estado otorgue dicha reparación. Pongo un ejemplo.

Al momento en el que el Estado mexicano violó uno de mis derechos, mi hija tenía ocho meses de nacida. Pasaron más de 10 años para que agotara los procedimientos nacionales; luego acudí ante la Comisión Interamericana de Derechos Humanos, la cual dictó una recomendación, y el resto del procedimiento. Finalmente, llegué a la Corte Interamericana que emitió sentencia. Pero si los presidentes que lleguen a gobernar a México no la quieren cumplir, dado que la corte no tiene mecanismos para obligar a los ciudadanos a cumplir con sus sentencias jurisdiccionales, yo debo esperar tres o más sexenios y ni mi hija, que para entonces tendrá más de 25 años y estará casada, ni yo podremos ver resarcido ese derecho.

Entonces, mi propuesta consiste en que la corte encuentre la manera de tomar parte del financiamiento de los programas interamericanos, por ejemplo, del que brinda el Banco Interamericano de Desarrollo, cuando haya una sentencia que cumplir en la que se estipule pagar a la víctima, cortándole así al Estado esa parte del presupuesto.

Por otro lado, considero que la participación de los abogados nacionales ante la corte es de suma importancia, en virtud de que ellos han seguido el caso durante todo el procedimiento nacional y cuando llega ante la Comisión Interamericana, ésta se lo asigna a sus abogados, quienes suelen tener mucho trabajo y poco tiempo para estudiar y defender el caso, y algo similar ocurre en la Corte Interamericana. ¿Por qué, entonces, no establecer de manera concreta la participación de los abogados nacionales en el procedimiento ante la comisión y la corte?

Existe también un problema en cuanto al apremio de los testigos. Los Estados miembros de la OEA tienen que presentar los testigos ante la corte en el procedimiento de las pruebas. Eso significa que el Estado, a veces, oculte la presencia del testigo en su país y asegure que se encuentra en el extranjero. Entonces, se deben esperar seis o doce meses para que el testigo aparezca; tiempo en el que quizá se le instruyó para que falsificara su declaración. Con el fin de evitar esto, propongo que la corte establezca mecanismos para obligar al Estado a decir en dónde se encuentran los testigos y emita una forma de búsqueda de los mismos para que se presenten ante la corte a declarar sobre los asuntos que ellos conocen. 
Medidas provisionales; en cuanto a las medidas provisionales hay que encontrar también mecanismos para hacer que estas sean más rápidas porque entre el momento de dictarlas y el momento de aplicarlas puede haber muchos daños irreparables.

La remisión de los asuntos ante la corte; como considero que esto es cuestión de presupuesto, me pregunto: ¿Por qué, entonces, no se establece una forma de impuesto especial para financiar los casos de la gente que no tiene dinero? Cuando se trate de una violación a los derechos de una persona con suficiente dinero para llevar su asunto ante la corte, pues que lo haga. Pero si una persona no tiene dinero para llevar a los abogados y pagar todo el procedimiento, es necesario dar una suficiente garantía jurisdiccional a nivel nacional o regional. Para esto deberán crearse fondos especiales para establecer abogados de oficio ante la Corte Interamericana que ayuden a las víctimas de escasos recursos.

\section{SUGERENCIAS}

\section{La permanencia de la Corte Interamericana}

Como se puede observar en el sistema europeo de protección de los derechos humanos, el cual dispone de una corte permanente para resolver los casos de violación de los derechos humanos, no cabe duda, que la permanencia de la corte, le permitirá actuar con rapidez y eficacia. Su calidad de permanente dará a sus integrantes la disposición del tiempo necesario para el estudio de los casos presentados ante este órgano y responder con eficacia a las demandas de las partes.

\section{La eliminación de la figura de juez ad hoc}

La asignación del juez ad hoc por los Estados, denunciados por presuntas violaciones de derechos humanos a sus ciudadanos, crea una situación de desequilibrio entre las partes, debido a que las víctimas de los abusos por parte del Estado y que han sufrido la negativa del Estado a restablecer sus derechos violados, tiene que confrontarse a nivel regional con un juez especial, designado por el Estado para defender su posición inicial. 
Consideramos que esta práctica (la posibilidad de asignar un juez ad hoc) constituye ella misma, una violación flagrante al derecho a la igualdad entre las partes.

3. Reconocer violación de los derechos humanos por particulares, grupos de particulares y personas morales del sector privado

Por ser un organismo regional de protección de los derechos humanos y tomando en cuenta las condiciones socioeconómicas de las sociedades americanas y los momentos políticos por los que atraviesa la región; consideramos que existen organizaciones (grupos armados, de presión y organizaciones políticas) que pueden violar los derechos comunitarios o individuales de las personas y refugiarse en el principio que señala que los derechos humanos solamente son violados por los funcionarios del Estado.

Además de que al no reconocer la violación de los derechos humanos por parte de estas organizaciones, se viola el principio de no impunidad, así como el derecho a la justicia, por tal motivo es necesario que el Sistema Interamericano de Derechos Humanos amplíe la protección contra los abusos y violaciones por parte de grupos y organizaciones no estatales.

4. Reconocimiento de los derechos humanos de los grupos de personas, comunidades o entidades sociales

A pesar de que la Corte Interamericana ha examinado en escasas ocasiones casos de violación de los derechos de algunos grupos de personas o comunidades, hace falta un reconocimiento tácito de los derechos de estos sujetos, para ofrecer a las víctimas de estos tipos de abusos, las bases jurídicas que les permitan solicitar el restablecimiento de sus derechos. Hay que tomar en cuenta que en América en general y en América Latina en particular existen diferentes derechos humanos clasificados como comunitarios o comunes a los pueblos, familias, entidades sociales o grupos étnicos que requieren de una legislación clara para su protección, petición o reparación en caso de ser violados. 


\section{Creación de un mecanismo de indemnización rápida de la víctima}

De acuerdo con las estadísticas, en relación con la ejecución de las recomendaciones y sentencias de los organismos regionales de protección de los derechos humanos, se registran retrasos prolongados en cuanto a las reparaciones fijadas por la comisión o la Corte Interamericana. Por tal motivo consideramos que el sistema interamericano de protección de los derechos humanos, debe de crear un mecanismo eficaz para obligar a los Estados a reparar los daños, sin demora, una vez que estos sean fijados por el órgano correspondiente del sistema

\section{La aceptación de los abogados nacionales para la defensa de las víctimas ante la Corte Interamericana}

Consideramos importante la participación de abogados nacionales a favor de las víctimas ante la Corte Interamericana, ya que ellos disponen del conocimiento del caso desde las instancias nacionales y tienen los elementos suficientes para defender a la víctima ante el Estado - supuesto violador - quien no ha querido reconocer y reparar los daños causados.

Por otro lado, se considera que la evolución de los derechos humanos en el continente americano y el desarrollo del sistema durante más de un cuarto de siglo, los logros obtenidos y el nivel de la eficacia alcanzada en la protección de los derechos humanos, nos permiten afirmar que el sistema interamericano ya está en posibilidad de incrementar la protección de los derechos fundamentales ante los grupos de presión o grupos de poder del sector privado (quienes pueden lesionar los derechos protegidos sea internacionalmente o a nivel regional), abriendo de esta manera el camino para que las instituciones del sistema atiendan las demandas de flagrante violación por particulares. Consideramos que el camino para este reconocimiento tácito de violación de los derechos humanos por particulares ha sido limpiado por diversos ordenamientos jurídicos nacionales, como en los casos de Colombia, Brasil, Argentina.

Es de suma importancia en el contexto americano que los grupos de interés tengan acceso a las instituciones regionales para pedir la reparación de sus derechos cuando consideren que éstos han sido violados por autoridades o particulares. Es cierto que la Corte Interamericana ha conocido algunos casos del género, pero es ya el momento de reconocer de manera tácita la competencia de la comisión y de la corte para atender las 
demandas de los grupos sean sociales, políticos o de otra índole en relación a una supuesta violación de sus derechos. Aunque los artículos 44 del estatuto de la comisión y el 23 del Reglamento de la Comisión se refieren a esta situación, en la práctica estas disposiciones son escasas.

Asimismo es el momento de que el nombramiento de un juez ad hoc sea limitado a los asuntos específicos o simplemente a los asuntos entre los Estados, para evitar vulnerar a los particulares quienes son sometidos a pruebas difíciles durante todo el procedimiento desde la justicia nacional. Así ante la comisión se ven obligados a asumir una vez más el peso del Estado todo poderoso con un abogado ad hoc ante la corte. Esta fórmula puede ser considerada como una violación más o una vulneración de la víctima.

La permanencia, la estabilidad y la constancia de una corte son los elementos importantes que podrían influir de una manera significativa en la efectividad, que se reflejaría en la rapidez de los procedimientos ante la Corte Interamericana de los Derechos Humanos. Por tal motivo, se sugiere a los miembros de la organización conjugar esfuerzos para asegurar un presupuesto que permita la permanencia de los miembros de la corte con el fin de impulsar la corte mediante la permanencia de sus jueces.

\section{BIBLIOGRAFÍA}

Convención Americana sobre Derechos Humanos, adoptada el 22 de noviembre de 1969.

Documentos Básicos en Materia de Derechos Humanos en el Sistema Interamericano, Washington, DC, Secretaría General de la Organización de los Estados Americanos, 2001.

Estatuto de la Corte Interamericana de los Derechos Humanos http:// www.sre.gob.mx/derechoshumanos/Camds.htm

Ferrer MaC-Gregor, Eduardo y CARbonell, Miguel, Compendio de Derechos Humanos, México, Porrúa, Comisión Nacional de los Derechos Humanos, 2004.

Gros Espiell, Héctor, La Convención Americana y la Convención Europea de Derechos Humanos. Análisis comparativo, Santiago de Chile, Editorial Jurídica de Chile, 1991. 